\title{
Laparoscopic surgery in the rat
}

\section{Beneficial effect on body weight and tumor take}

We read with interest the paper from Drs. Bouvy et al. [2], who have provided some helpful insights into the behavior of malignant tumor cells during laparoscopic surgery. As with work previously reported by Allendorf et al. [1], they have demonstrated that laparoscopic procedures may be associated with reduced growth of tumor cells in a smallanimal model. This may be due to reduced physiological stress in animals undergoing laparoscopic surgery, resulting in less perioperative suppression of the immune system.

However, we would caution readers not to draw the conclusion that laparoscopic approaches to the resection of abdominal malignancy are safe. In Dr. Bouvy's study, cancer cells were not introduced into the peritoneal cavity until after the surgical procedure was concluded. Therefore the potential for cancer cells to be redistributed by the insufflation of $\mathrm{CO}_{2}$ gas and cause wound metastases was not tested.

Our own recent experience [4] with laparoscopic and open surgical laceration of an implanted adenocarcinoma in a rat model has demonstrated a fivefold increase in the incidence of metastases in the abdominal access wounds of rats undergoing laparoscopic surgery despite the advantage of reduced growth of the implanted "primary" tumor. Similar results have been reported by Jones et al. [3] following the introduction of free tumor cells into the abdominal cavity at the commencement of either laparoscopy with $\mathrm{CO}_{2}$ insufflation or laparotomy in a hamster model. These studies suggest that if cancer cells are liberated during prolonged $\mathrm{CO}_{2}$ insufflation, metastatic implantation and growth in abdominal wall wounds is more common following laparoscopic surgery. Interestingly, a further experiment using the same implanted tumor model in our institution during laparoscopic tumor laceration at both gasless and conventional laparoscopy demonstrated a threefold reduction in the incidence of wound metastases following gasless laparoscopy (unpublished data).

It would be interesting to repeat the experiments per- formed by Drs. Bouvy et al. with the tumor cells introduced into the peritoneal cavity at the commencement rather than the conclusion of the laparoscopic and open surgical procedures. The effect of pneumoperitoneum would then be directly tested and the pattern of tumor implantation might be significantly altered. Until the issue of laparoscopic dissemination of malignant cells is fully understood, patients should not undergo laparoscopic surgery for malignancy outside the context of controlled clinical trials.

\section{References}

1. Allendorf JDF, Bessler M, Kayton ML, Oesterling SC, Treat MR, Nowygrod R, Whelan RL (1995) Increased tumor establishment and growth after laparotomy vs laparoscopy in a murine model. Arch Surg 130: 649-653

2. Bouvy ND, Marquet RL, Hamming JF, Jeekel J, Bonjer HJ (1996) Laparoscopic surgery in the rat: beneficial effect on body weight and tumor take. Surg Endosc 10: 490-494

3. Jones DB, Guo L-W, Reinhard MK, Soper NJ, Philpott GW, Connett J, Fleshman JW (1995) Impact of pneumoperitoneum on trocar site implantation of colon cancer in hamster model. Dis Colon Rectum 38: $1182-1188$

4. Mathew G, Watson DI, Rofe AM, Baigrie CF, Ellis T, Jamieson GG (1996) Wound metastases following laparoscopic and open surgery for abdominal cancer in a rat model. Br J Surg 83: 1087-1090

\section{I. Watson \\ G. Mathew}

The Royal Adelaide Centre for Endoscopic Surgery

Department of Surgery

Royal Adelaide Hospital

North Terrace

Adelaide

South Australia, 5000

Australia 